\title{
Road Safety Audit and Comparison with Accident Case Studies
}

\author{
K. Durga Abhishek, K. Yogesh Kumar, and R. Vijayalakshmi* \\ Department of Civil Engineering, Siva Subramania Nadar College of Engineering, Kalavakkam - 603110, \\ Tamil Nadu, India; sonu.d8k@gmail.com, k.yogeshkumar481@gmail.com, \\ vijayalakshmir@ssn.edu.in
}

\begin{abstract}
Objective: Road Safety Audit (RSA) gives scope for the reduction of accidents and helps us to provide safe, self-explaining and efficient roads. Analysis: The road safety audit was done for a stretch of $10 \mathrm{~km}$ from Kelambakkam Junction to VIT Chennai located at Kelambakkam to Vandalur Road- SH 121 in India. In this Road safety audit, the accident analysis was done by considering geometric features of the road, pedestrian safety, and accident-prone locations. The accident data for past 4 years 2015 - 2018 was considered and compared the RSA data with various identified accident case studies in that stretch. Findings: After conducting RSA, it was found that the effective width of carriageway was reduced by the trucks, which were parked on highway, and creating traffic hindrance to high speed moving vehicles. Numbers of street lights are not sufficient and most of the Street lights are not working properly throughout the stretch. Median openings were found at unauthorized places which should be immediately closed, Access and service lanes are also deficient which requires immediate improvement. Growth of uncontrolled vegetation on either side of the road should be removed. Road and median markings which are found missing should be corrected and speed signs should be indicated at various places. This study will be more useful if the RSA data would be updated, and the reason behind each accident, are recorded and corrective measures taken. Application: This research can be used by the government officials to monitor and alter the road conditions as per IRC codes. It aids in rectifying and reducing the future accidents.
\end{abstract}

Keywords: Accident Analysis, Data Improvement

\section{Introduction}

Road Safety Audit (RSA) is one of the effective methods for improvement of road safety; in which experts attempt to identify potentially dangerous features on the highway environment and suggest remedial measures. RSA is nothing but a systematic approach for the proper evaluation of existing old road or new roads by an independent audit team at the stages of planning, design, construction, operation and maintenance to achieve accident free roads and to enhance overall safety performance ${ }^{1}$. Initially Road Safety Audit was carried out in Great Britain in 1980, which is now spread in different countries around the world. The RSA system which was established in UK, later spread to USA, Denmark, Canada, and New Zealand, China, Japan Australia and now it is being used as a tool in many countries for the formulation of guidelines and planning of their trunk roads ${ }^{2,3}$. Now the importance of road safety audits is being realized in India. It is because of the effort of Ministry of Road Transport and Highways (MRTH). The project on: Development of Safety Audit Methodology for Existing Roadway Sections was sponsored by MRT|H to Central Road Research Institute on April 2002.

The objective of this work is to (i) To analyse accident prone zones of SH 121 (ii) Collection of accident data for the stretch (iii) To conduct RSA and determine the pros and cons in the existing road (iv) Analysis of the prob-

*Author for correspondence 
lem statement (v) To compare the safety audit data with various accident case studies and concluding a solution to the problem (vi) To provide new possibilities as per IRC codes to the transport department in order to improve the standards of exist ting road.

\section{Methodology}

The Scope of this RSA work is to improve the standards of the existing roads, to reduce the rate of accidents, reduction of traffic congestion, to deduce the conflict points and to increase road user's safety. The steps carried out for the RSA are shown in the flow chart in Figure 1.

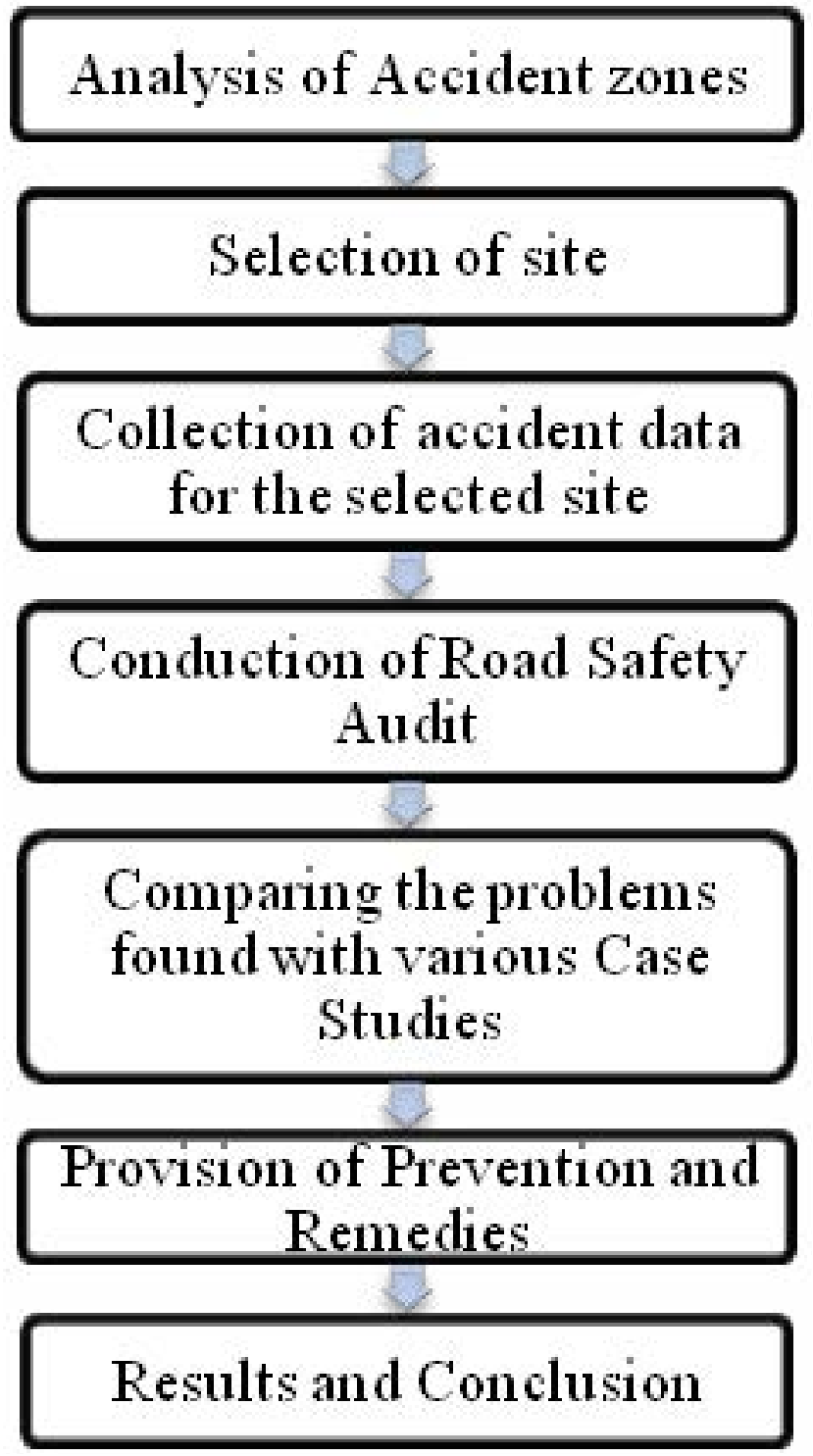

Figure 1. Methodology for road safety audit.

\subsection{Analysis of Accident Zones}

The accident data was collected for most Vulnerable Stretches surrounding Chennai at Transport Commissionerate Office, Chepauk, and Chennai in India. The following are the routes, for which the data was collected.

National Highways (NH):

1. Guduvancheri road (NH 45)

2. Vandalur - Perungalathur road (NH 45)

3. Tambaram - Chrompet road (NH 45)

4. OMR - Thuraipakkam road ( $\mathrm{NH} 45)$

5. Maduranthakam road ( $\mathrm{NH} \mathrm{45)}$

State Highways (SH):

1. Vandalur - Kelambakkam road (SH-121)

2. Thiruporur road (SH-49A)

3. Kelambakkam - ECR (SH-49)

4. ECR road - Mahabhalipuram (SH-49)

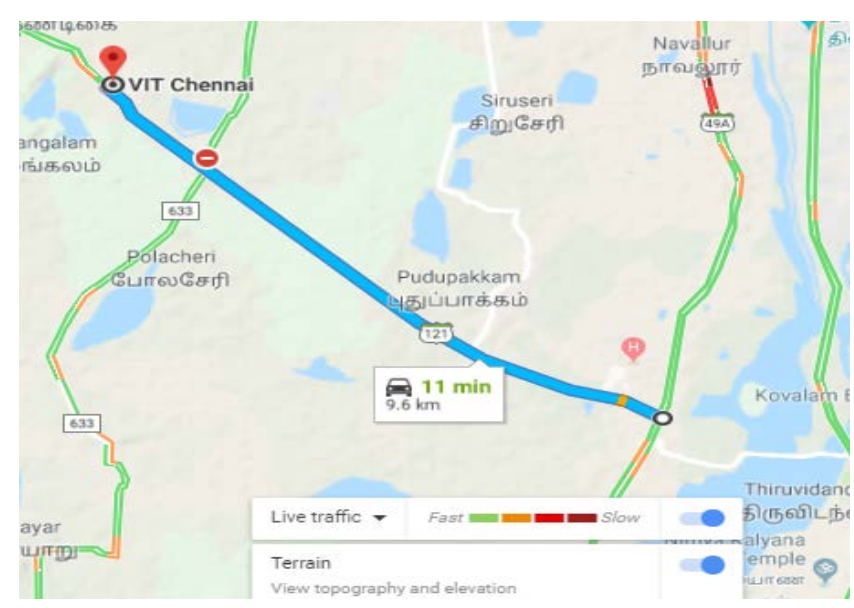

Figure 2. Location map with terrain and traffic details.

\subsection{Selection of Site}

From the above-mentioned routes, we have selected the Vandalur - Kelambakkam road (SH-121), Tamilnadu, India for our survey. The selected highway stretch has been an existing road in which it serves as a connecting road for Vandalur road (NH-45) and Old Mahabalipuram Road (SH-49A). From the analysis of the accident zones, it is noted that this road is one of the most vulnerable road in terms of Accidents, which leads to fatalities. We have conducted the audit for a stretch of $10 \mathrm{~km}$ starting from Kelambakkam $(0 \mathrm{~km})$ to VIT, Chennai $(10 \mathrm{~km})$. This stretch comprises important junctions like Velichai, Pudhupakkam, Mambakkam and VIT, Chennai. The 
location map with Terrain and traffic image is shown in Figure 2.

\subsection{Salient Features of the Study Segment}

The selected stretch was the 4-lane two-way traffic State Highway (SH-121). Main Carriageway width is $7.00 \mathrm{~m}$ wide, $1.5 \mathrm{~m}$ earthen shoulder available on either side of the road and median width of $1 \mathrm{~m}$. Cross section of state highway is shown in the Figure 3. Road infrastructure details are as under.

Major Junctions : 5

Bus Bays : : 1

No. of schools : 3

No. of hospitals nearby : (i) Chettinad hospital at 0.5 $\mathrm{km}$ from Kelambakkam,

(ii) Government Health centre at Kelambakkam.

Latitude \& Longitudes : At Kelambakkam: 12.789844, 80.221474.

At VIT, Chennai: 12.839582, 80.153410.

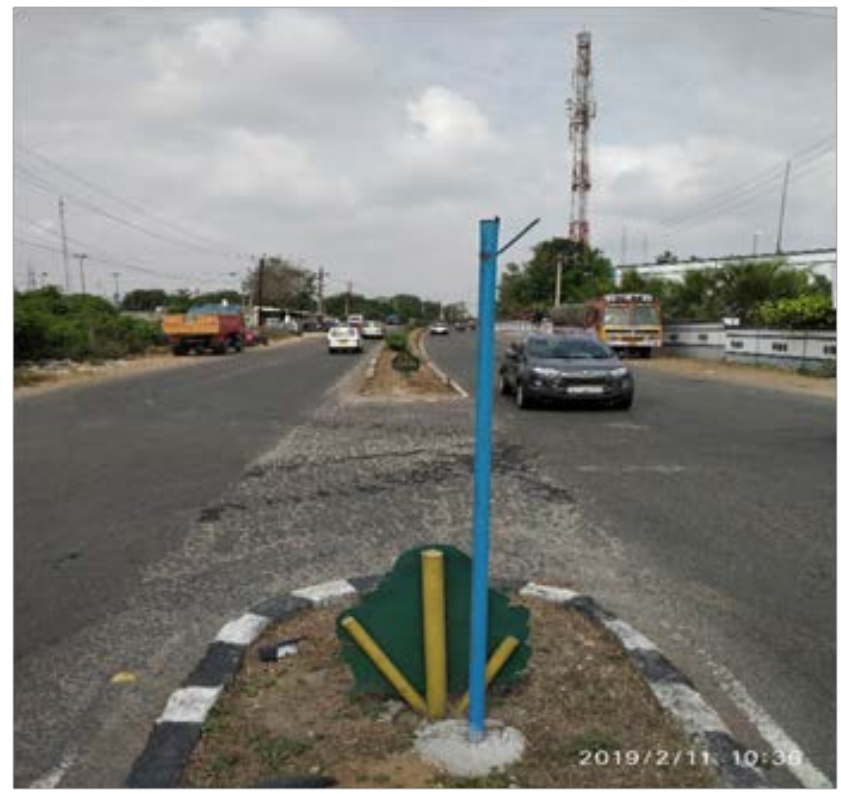

Figure 3. Cross section of Vandalur - Kelambakkam road.

\subsection{Collection of Accident Data}

For the selected State highway stretch, the accident data were collected from Kelambakkam Police station. The accident data were collected for a period of four years from 2015to 2019. The accident data available from police records consisted of the location of accident and the details of severity of accidents, namely, fatal and non - fatal.

\subsubsection{Summary of Accidents Detail of SH-121 of Study Area}

The bar chart showing the details of accident data is given in Figure 4. It was also observed that minor accidents were ignored in many cases where as severe accidents involving loss of life or serious injuries were most often reported. Summary of accidents detail of study stretch of State Highway 112 has been shown in Bar Chart. The chart states that an average of 10 accidents is happening for last 4 years and an average of four fatal accidents are happening for past 4 years.

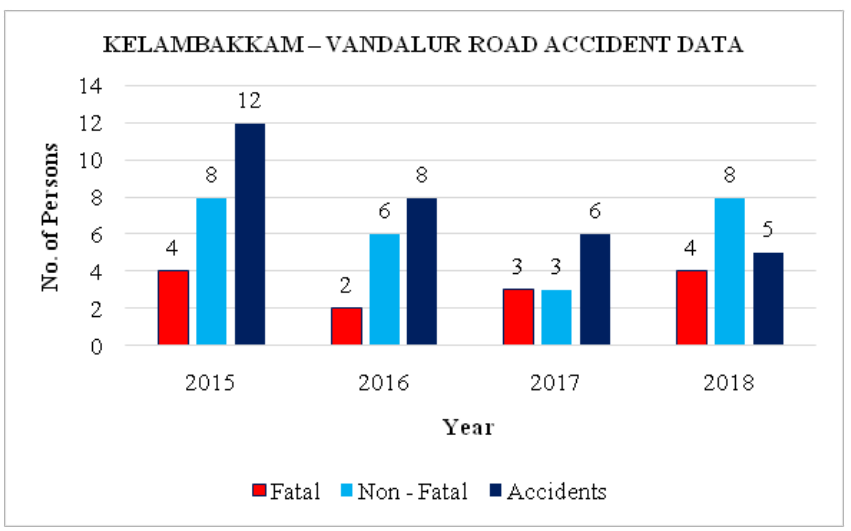

Figure 4. Bar chart of accident data.

\subsection{Conduct of Road Safety Audit Data}

The road safety audit was done for a stretch of $10 \mathrm{~km}$ from Kelambakkam Junction to VIT Chennai located at Kelambakkam to Vandalur Road- SH 121. The RSA was conducted with all safety measures and as per the norms. The following points are said to be the main problems found in that stretch of road after doing the Road Safety Audit,

1. Road markings are not visible throughout the entire stretch of road.

2. Growth of uncontrolled vegetation on either sides of the road is a serious issue in the Vandalur to Kelambakkam road, which makes the following miseries:

i. Proper shoulder width is not available due to growth of vegetation up to the end lane marking.

ii. Parking cannot be done since minimum shoulder width is not available.

3. No Street lights throughout the entire stretch of the road. 
4. Proper signboards are not placed in many aspects of the road. The main signboards that are required in the road are,
i. Gap in median
ii. U-turn or No U-turn
iii. Bus stop
iv. School Zone
v Speed Limit
vi Dangerous curve ahead

5. Improper lightings in important junctions and bus stops.

6. Retro reflectors are not placed/not working in many aspects of the road.

7. No speed breakers available on the adjoining roads that connect to this road.

8. Name boards of towns are not properly placed and maintained.

\subsection{Comparison of RSA Data with Previous Accident Case Studies}

Problem 1: Growth of vegetation on the road sides IRC Code Violated: IRC SP 021: Guidelines on Landscaping and Tree Plantation As per the IRC code IRC SP 021, From Clause 10.3, it states that

Selective pruning or cutting of trees and shrubs will be required at situations where these

i. interfere with sight distance,

ii. come in the way of effective street illumination,

iii. are too close to the carriageway so as to be hazardous

Accidents Occurred: Two persons killed in road accidents - The Hindu Dated: August 10, 2010

The news article states that, a motorcyclist died when he rammed into a stationary lorry near Vengambakkam bus stop on Vandalur - Kelambakkam Road. The lorry was parked on the road side after one of its tyre punctured. From the article, it is observed that the lorry was parked on the road lane either due to unavailability of shoulder width or growth of vegetation on the shoulder (Figure 5a). This is a serious problem for road users both in day and night time (Figure $5 \mathrm{~b}$ ).

Solution to the problem: Growth of vegetation on the road side has been a serious issue in the road safety process and the maintenance of the growth should be done periodically. Hence various other measures can be taken to reduce the growth of vegetation on the road sides. Some of the measures are, (i) Herbicides can be used in management of annual and perennial, herbaceous vegetation in field and roadside plots (ii) Ornamental plant species which have aesthetic value and pollution tolerance are recommended for planting along the roads. The Conclusion for the problem is to properly maintaining the vegetation growth on the sides. Hence the maintenance of growth of vegetation on the road side should be considered as a serious issue and has to be maintained periodically as per the IRC SP 021.

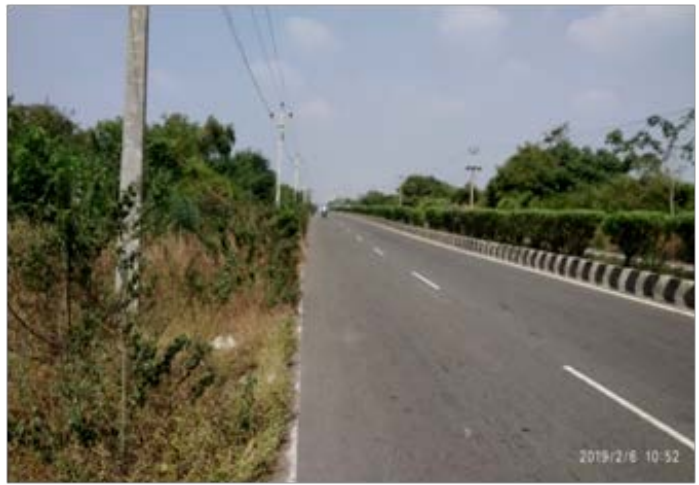

(a)

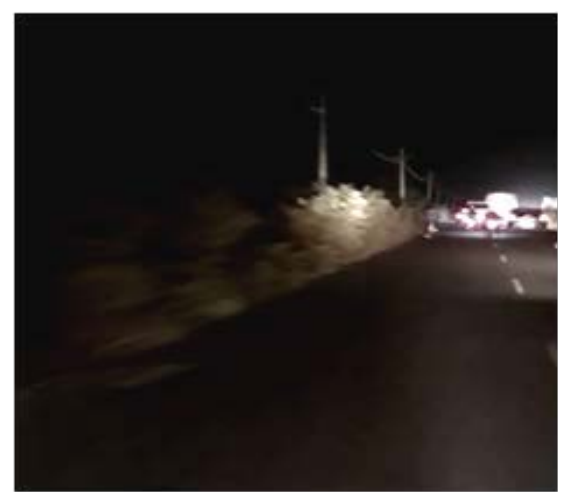

(b)

Figure 5. IRC codal violations. a. Growth of vegetation. b. Interference with sight distance.

Problem 2: Shoulder and road level is not equal and side barricades are not available

IRC Code Violated: IRC 086: Geometric Design Standards for Urban Roads

IRC SP 842014 - Manual of Specifications and Standards for Four Laning of Highways

As per the codes mentioned, the following violations were observed in the road safety audit. 
1. As per the IRC 086 clause 8.3, the road level and the shoulder level should be equal. But in many places throughout the stretch, proper shoulder width is not provided and the shoulder and road level are not equal.

2. As per IRC SP 84, proper guardrails should be provided in curves of highways. In this case, guardrails are not provided.

Accidents Occurred: Class VII girl crushed to death under her school van- The New Indian Express. The news article states that, A Class VII student died and her younger sister and eleven other children suffered injuries when a van overturned on the Vandalur - Kelambakkam road. The accident occurred due to, the driver tried to overtake a speeding lorry. While doing so, he drove over a pothole and lost control of the vehicle. The sisters seated right next to the door were thrown out and Nethra was run over by the van's rear tyre. The van overturned off the road, injuring all the children inside.

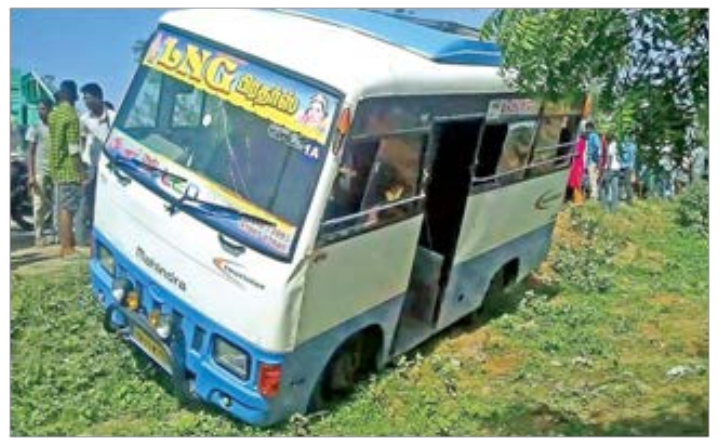

(a)

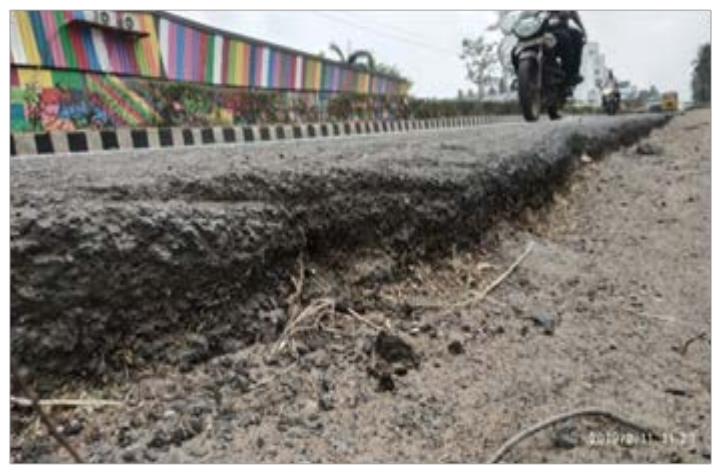

(b)

Figure 6. Accident occurred due to difference in level of road and shoulder. a. Road Accident. b. Shoulders and road level not equal.
Solution to the problem: Maintaining of shoulder level with the road level is very much important since that space acts as the parking space in highways. Hence the following measures can be taken to maintain the road level and the shoulder level.

1. Proper earth material should be filled up in the shoulder after the laying of a new road.

2. Guard rails should be provided in the curves of roads in order to avoid the overtopping of vehicles to the side.

Conclusion for the problem is, by properly maintaining the shoulder level and the road level two wheeler accidents and vehicle roll over problems can be reduced. Increase shoulder widths can be used as parking area as shown in Figure 6.

\section{Conclusion}

i. Carrying out of regular or needy maintenance and markings of road safety signs is needed.

ii. Provision of street lights for the whole stretch is needed.

iii. Provisions of proper retro reflectors are needed for the whole stretch.

iv. Provision of proper footpaths for pedestrians and pedestrian crossings at intersections near habitation is needed

v. Closure of all unauthorized median openings and adequate provisions for crossing local people be made on priority.

vi. Parking on the road is should be as per traffic rules.

vii.Clearance and maintenance of vegetation on shoulder is needed for efficient road use.

viii. Carrying out of regular repairs and maintenance of the carriage way is needed.

ix. Removal of road side obstructions present on the shoulder is needed.

x. Provision of proper Bus bay lanes and maintenance of bus stops is needed for the whole stretch.

xi. Provision of proper width, height and vegetation on median is needed.

xii. Clearance of concrete poured on the roads is needed.

xiiiProvision of speed breakers on the intersecting minor roads.

These are the remedies/measures needs to improve the safety of that road. From the case studies, though majority 
of the accidents are driver's fault, road provisions are also one of the main reasons for those accidents. Hence, it is essential to provide various measures, which is stated by this report to increase the road safety.

\section{References}

1. Jain SS, Singh PK, Parida M. Road safety audit for four lanes National Highway. International Conference on Road Safety and Simulation. Indianapolis USA; 2011. p. 1-22.
2. Arun SB, Dheeraj NK. Road safety audit. IOSR Journal of Mechanical and Civil Engineering. 2012; 1(6):1-8. https:// doi.org/10.9790/1684-0160108

3. Krunal B, Nekzad K, Zala LB. Road safety audit: A case study Navsari to Chikhli National Highway 48. International Journal of Latest Engineering and Management Research. 2017; 2(3):35-8. 